\title{
Linfoma Primário do Pericárdio: Uma Entidade Rara
}

\section{Primary Pericardial Lymphoma: A Rare Entity}

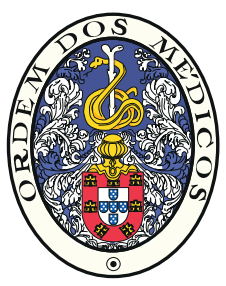

Sara MAGALHÃES $\triangle^{1}$, Ivo FERREIRA ${ }^{1}$, Raquel THEMUDO²

Acta Med Port 2016 Nov;29(11):762-762 - http://dx.doi.org/10.20344/amp.7205

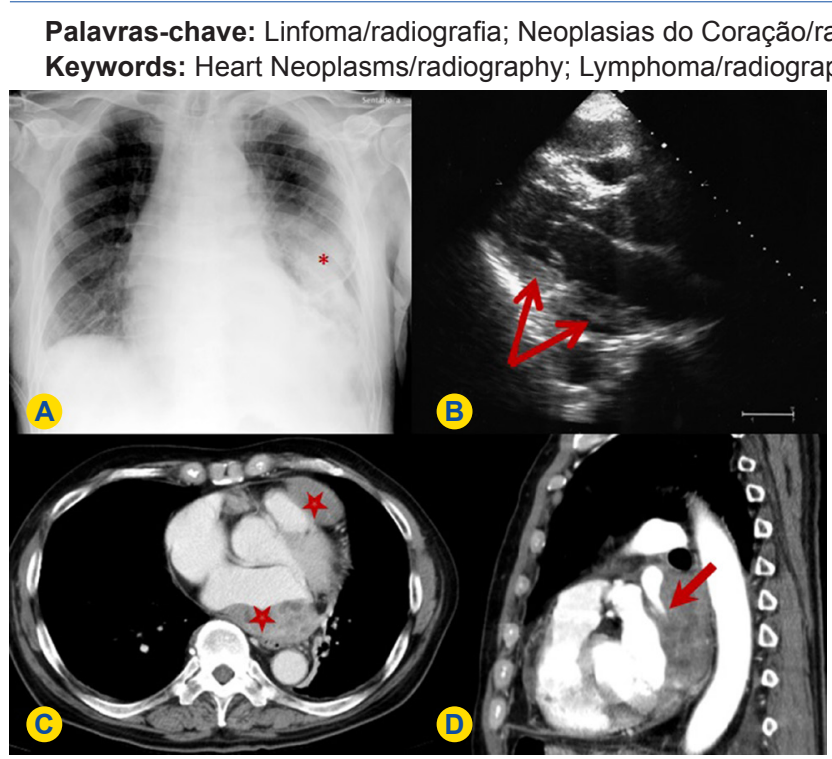

Figura 1 - A: Radiografia torácica: achados inespecíficos, nomeadamente aumento da silhueta cardiomediastinica. Consolidação 'em toalha' do lobo inferior esquerdo, correspondendo a pneumonia $\left(^{*}\right)$. B: Ecocardiograma transtorácico: lesão expansiva que atinge o ventrículo esquerdo (seta bifurcada), em relação com lesão extrínseca. C e D: tomografia computorizada axial e sagital, respectivamente, revelando lesão expansiva envolvendo as cavidades cardíacas (estrela), com realce heterogéneo após administração do produto de contraste, afilando a veia pulmonar esquerda (seta), achados em relação com linfoma pericárdico. A etiologia primária ou secundária depende do atingimento de outras cadeias ganglionares que, no presente estudo, eram negativos.

Doente do sexo masculino, 74 anos, recorreu ao serviço de urgência por quadro de palpitações, dispneia para pequenos esforços e anorexia com perda de peso recente. Ao exame objectivo apresentava sons cardíacos e pulmonares ensurdecidos, sem alterações valorizáveis no estudo analítico. No electrocargiograma apresentava flutter auricular com resposta ventricular rápida. Por esse motivo realizou uma radiografia torácica (Fig. 1A) e ecocardiograma transtorácico (Fig. 1B) que mostrou a presença de uma massa infiltrativa difusa iografia; Pericárdio; Ressonância Magnética.

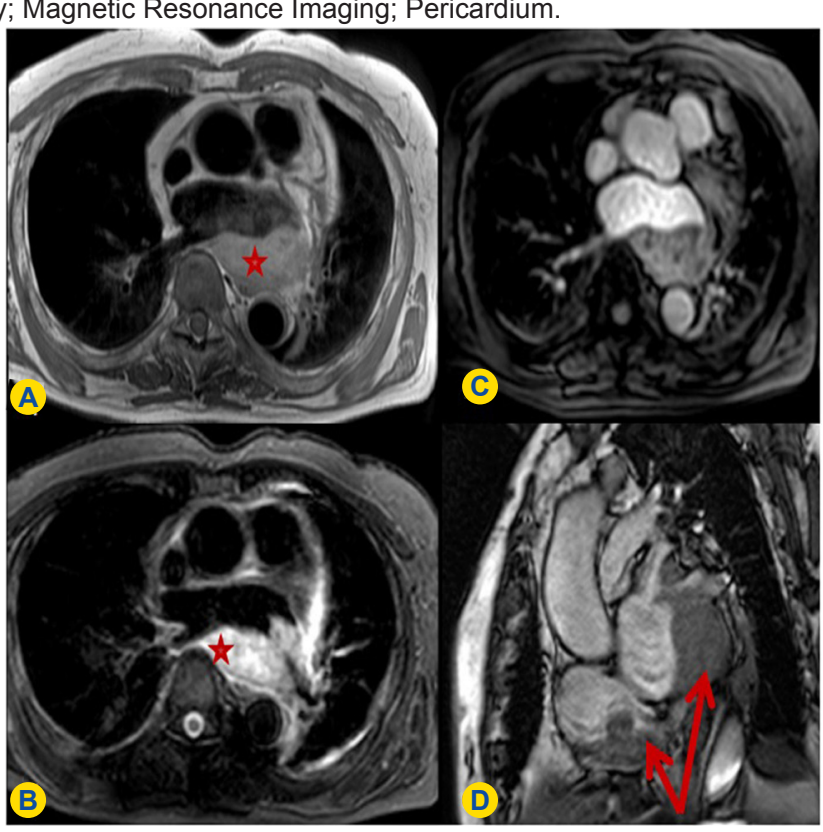

Figura 1 - A: ressonância magnética sequência axial T1 - lesão iso/levemente hiperintensa e heterogénea (estrela); B: Lesão hiperintensa em sequência axial T2 com saturação de gordura (estrela); C: Realce heterogéneo após administração de contraste ev; D: Sequência cine eixo curto mostrando a invasão extrínseca (seta bifurcada). A avaliação funcional cardíaca não mostrava outras alterações de relevo.

envolvendo as câmaras cardíacas esquerdas. Realizou tomografia computorizada toracoabdominopélvica (Fig.s 1C e D) e ressonância magnética cardíaca (Fig. 2) para caracterização adicional. $\mathrm{O}$ diagnóstico histológico foi de linfoma primário grandes células $\mathrm{B}$ do pericárdio, entidade rara com maior prevalência em doentes imunodeprimidos e na faixa etária 60 anos. ${ }^{1-4} \mathrm{~A}$ clínica é fruste e o diagnóstico é imagiológico e histológico. Tem mau prognóstico, sendo recomendada quimioterapia paliativa na maioria dos casos. O doente faleceu com intercorrência pulmonar infeciosa.

\section{REFERÊNCIAS}

1. Jeudy J, Kirsch J, Tavora F, Burke AP, Franks TJ, Mohammed TL, et al. Cardiac lymphoma: radiologic-pathologic correlation. Radiographics. 2012,32:1369-80.

2. Pérez Baztarrica G, Nieva N, Gariglio L, Salvaggio F, Porcile R. Primary cardiac lymphoma: a rare case of pulmonary tumor embolism. Circulation. 2010;121:2249-50.

3. Rodrigues $\mathrm{H}$, Donato $\mathrm{P}$, Oliveira PB, Franco F, Marques C. Tumores cardíacos primários: revisão bibliográfica e da casuística dos Hospitais da Universidade de Coimbra. Acta Radiol Port. 2004;16:19-25.

4. Matos AP, Palas J, Doulaptsis C, Ramalho M, Duarte S, Bogaert J. B-cell lymphoma of the heart: a rare diagnosis. Rev Port Cardiol. $2014,33: 803$.

1. Serviço de Doenças Infecciosas. Hospital de Curry Cabral. Centro Hospitalar de Lisboa Central. Lisboa. Portugal.

2. Serviço de Dermatovenereologia. Hospital de Curry Cabral. Centro Hospitalar de Lisboa Central. Lisboa. Portugal.

$\triangle$ Autor correspondente: Diana Póvoas.d.povoas@gmail.com

Recebido: 20 de setembro de 2015 - Aceite: 29 de dezembro de 2015 | Copyright @ Ordem dos Médicos 2016 